\title{
SINTESIS SENYAWA ALIL ISOEUGENOL ETER DAN PRODUK REAKSI PENATAAN ULANG CLAISENNYA
}

\author{
Rachmawati Ningsih ${ }^{1}$ \\ ${ }^{1}$ Jurusan Kimia Fakultas Sains dan Teknologi UIN Maliki Malang
}

\begin{abstract}
ABSTRAK
Telah dilakukan penelitian untuk mempelajari reaksi alilasi isoeugenol dan produk penataan ulang Claisennya. Reaksi substitusi gugus alil pada isoeugenol dilakukan dengan pemanasan pada suhu $55^{\circ} \mathrm{C}$ selama 8 jam. Reaksi penataan ulang Claisen alil isoeugenol eter dilakukan selama 30 menit. Produk reaksi dianalisis dengan spektrofotometer IR, GC dan GC-MS. Pada spektra GC-MS hasil reaksi yang didukung oleh spektra IR, menunjukkan bahwa reaksi alilasi isoeugenol menghasilkan produk campuran alil isoeugenol eter dan 6-alil-isoeugenol dengan kemurnian masing-masing 11,19\% dan 82,13\%. Analisis GC-MS memberikan dua puncak yang memiliki berat molekul sama, yaitu $204 \mathrm{gram} / \mathrm{mol}$. Pemanasan produk hasil alilasi isoeugenol pada suhu $200^{\circ} \mathrm{C}$ memberikan kemurnian sebesar 60,33\%.
\end{abstract}

Kata Kunci : Alil isoeugenol eter, 6-alil-isoeugenol, Penataan ulang Claisen

\begin{abstract}
ABTRACT
Study of isoeugenol allylation reaction and its Claisen rearrangement product has been investigated. Reflux method was used in isoeugenol allylation synthesis. The reagents were heated at $55^{\circ} \mathrm{C}$ for 8 hours. Claisen rearrangement was carried out for 30 minutes. Reaction product was analyzed by spectrophotometer IR, GC and GC-MS. Mixture product was showed in GC-MS spectra by two same molecule weight which is $204 \mathrm{gram} / \mathrm{mole}$. Purity of allyl isoeugenol ether and 6-allyl isoeugenol are 11,19 $\%$ and $82,13 \%$ respectively. Claisen rearrangement reaction was done in $200^{\circ} \mathrm{C}$ and the purity of the product is $60,33 \%$.
\end{abstract}

Key words : Ally isoeugenol ether, 6-allyl-isoeugenol, Claisen rearrangement

\section{PENDAHULUAN}

Penelitian-penelitian tentang kajian reaksi kimia yang menggunakan panas sebagai energi pengaktivasi untuk mengubah reaktan menjadi produk, telah banyak dilakukan. Arsen'ev, et al. (2003) melakukan beberapa rangkaian reaksi substitusi gugus alkil ke senyawa-senyawa golongan piridazin dengan energi panas (refluks) selama 30 menit. Crivello, et al. (1999) melakukan reaksi isomerisasi gugus alkil dan aril alil eter dari 1propenil eter dengan metode refluks. Sintesis senyawa alkil tiosianat, alkil sianida, alkil azida dan alkil aril eter dalam metil sianida dan air juga dilakukan dengan metode pemanasan (Tamami \& Ghasemi, 2008).

Penataan ulang Claisen didasari oleh penataan ulang sigmatropik, yaitu reaksi serentak dengan suatu atom atau gugus yang terpisah dari satu atom ke atom yang lain di sepanjang sistem elektron $\pi$ terkonjugasi. Teori yang mendukung reaksi penataan ulang Claisen adalah interaksi orbital HOMO dan LUMO. Interaksi ini sangat dipengaruhi oleh gugus-gugus yang terikat dalam sistem elektron $\pi$ konjugasi. Panas yang dibutuhkan akan dipengaruhi oleh substituen yang terikat pada senyawa induk. Kajian reaksi penataan ulang pada senyawa alil eugenol eter telah dilakukan sebelumnya oleh Suryanto (1996) dan diperoleh kondisi optimum reaksi penataan ulang Claisen alil eugenol eter menjadi 6-alil eugenol atau 4,6-dialil-2metoksifenol pada pemanasan dengan suhu 200 ${ }^{\circ} \mathrm{C}$ selama 30 menit. Tingkat kemurnian produk yang dihasilkan dan rendemennya masingmasing yaitu $90,62 \%$ dan 59,19\%. Perbedaan struktur antara senyawa alil isoeugenol eter dan alil eugenol eter terletak pada substituen yang terikat di posisi empat cincin aromatis. Senyawa alil isoeugenol eter mengikat gugus prop-1-enil, sedangkan alil eugenol eter mengikat gugus prop-2-enil atau gugus alil. Ini 
akan mengakibatkan kebutuhan panas alil isoeugenol eter untuk mengalami reaksi penataan ulang Claisen berbeda dengan alil eugenol eter. Hal tersebut merupakan masalah yang menarik untuk dikaji lebih lanjut. Dalam penelitian ini akan diamati pengaruh panas dan substituen terhadap penataan ulang Claisen senyawa alil isoeugenol eter selama proses sintesis senyawa tersebut.

Wei Tsai, et al. (2004) telah melakukan serangkaian reaksi alilasi dan penataan ulang Claisen terhadap senyawa-senyawa turunan fenol. Hasil penelitian tersebut diperoleh rendemen produk penataan ulang Claisen sebesar $80-87 \%$.

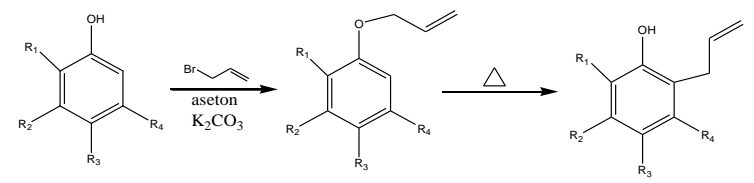

Gambar 1. Reaksi alilasi dan penataan ulang clasien

Keterangan :

$\mathrm{R}_{1}=\mathrm{R}_{2}=\mathrm{R}_{3}=\mathrm{R}_{4}=\mathrm{H}$

$\mathrm{R}_{1}=\mathrm{R}_{2}=\mathrm{R}_{4}=\mathrm{H}, \mathrm{R}_{3}=\mathrm{CH}_{3}$

$\mathrm{R}_{1}=\mathrm{R}_{2}=\mathrm{R}_{4}=\mathrm{H}, \mathrm{R}_{3}=\mathrm{OCH}_{3}$

$\mathrm{R}_{1}=\mathrm{R}_{2}=\mathrm{R}_{4}=\mathrm{H}, \mathrm{R}_{4}=\mathrm{Cl}$

$\mathrm{R}_{1}=\mathrm{R}_{2}=\mathrm{R}_{3}=\mathrm{H}, \mathrm{R}_{4}=\mathrm{COCH}_{3}$

$\mathrm{R}_{1}=\mathrm{R}_{3}=\mathrm{R}_{4}=\mathrm{H}, \mathrm{R}_{2}=\mathrm{COCH}_{3}$

$\mathrm{R}_{1}=\mathrm{R}_{2}=\mathrm{R}_{4}=\mathrm{H}, \mathrm{R}_{3}=\mathrm{C}\left(\mathrm{CH}_{3}\right)_{3}$

$\mathrm{R}_{1}=\mathrm{CH}\left(\mathrm{CH}_{3}\right)_{2}, \mathrm{R}_{2}=\mathrm{R}_{3}=\mathrm{H}, \mathrm{R}_{4}=\mathrm{C}$

Pada struktur eugenol, ikatan rangkap dua gugus alil terisolasi terhadap cincin benzena, sedangkan pada struktur isoeugenol, ikatan rangkap dua gugus prop-1-enil terkonjugasi terhadap cincin benzena. Hal ini menyebabkan isoeugenol memiliki jalan sistem delokalisasi elektron $\pi$ yang lebih panjang daripada eugenol dan tingkat energi yang lebih rendah daripada eugenol. Substituen yang cenderung sebagai penarik elektron akan menurunkan energi orbital HOMO dan LUMO, sedangkan substituen yang cenderung sebagai pendorong elektron akan menaikkan energi orbital HOMO dan LUMO. Substituen yang memberikan efek terjadinya konjugasi ekstra pada struktur molekul secara keseluruhan akan menaikkan energi orbital HOMO dan menurunkan energi orbital LUMO (Fleming, 1989).

Gugus prop-1-enil cenderung sebagai penarik elektron bila dibandingkan dengan gugus alil. Hal ini dimungkinkan akan menyebabkan tetapan laju reaksi penataan ulang Claisen alil isoeugenol eter lebih besar daripada alil eugenol eter.

Pada senyawa alil isoeugenol eter, gugus prop-1-enil yang terkonjugasi dengan cincin aromatis memperpanjang jalur delokalisasi elektron $\pi$. Adanya konjugasi ekstra dapat menaikkan energi orbital HOMO dan menurunkan energi orbital LUMO. Keadaan ini akan memperkecil selisih energi antara orbital HOMO dan LUMO, sehingga energi panas yang diperlukan untuk berlangsungnya reaksi penataan ulang Claisen rendah. Atas dasar teori ini, diperkirakan reaksi penataan ulang Claisen pada alil isoeugenol eter akan berlangsung pada temperatur yang lebih rendah dibandingkan alil eugenol eter. Dalam penelitian ini sintesis senyawa alil isoeugenol eter dilakukan dengan metode pemanasan (refluks) pada suhu $55^{\circ} \mathrm{C}$ selama 8 jam.

\section{METODOLOGI PENELITIAN \\ 2.1. Sintesis Alil Bromida}

Sebanyak $125 \mathrm{~g}(84,5 \mathrm{~mL})$ asam bromida $47 \%$ dimasukkan ke dalam labu leher tiga kapasitas $250 \mathrm{~mL}$ yang dilengkapi pengaduk mekanik, corong pisah dan pendingin bola. Kemudian ditambahkan 37,5 g (20 mL) asam sulfat pekat $97 \%$ tetes demi tetes melalui corong pisah sambil diaduk. Setelah selesai penambahan, ditambahkan $29 \mathrm{~g}(34 \mathrm{~mL})$ alil alkohol $99 \%$ tetes demi tetes. Lalu diteruskan dengan penambahan $37,5 \mathrm{~g}(20 \mathrm{~mL})$ asam sulfat pekat tetes demi tetes melalui corong pisah dimana pengaduk tetap dalam keadaan berputar. Campuran tersebut terjadi refluks tanpa pemanasan selama 60 menit. Untuk menangkap gas yang mungkin keluar, maka kondensor dihubungkan dengan gelas kimia berisi air melalui suatu selang. Setelah proses refluks selesai, labu didinginkan dengan wadah yang berisi es dan dibiarkan selama 20 menit. 
Kemudian campuran dipindahkan ke dalam corong pisah dan terbentuk dua lapisan, lapisan bawah (B-1) dipisahkan sedangkan lapisan atas (A-1) diekstrak dengan $100 \mathrm{~mL}$ larutan natrium karbonat $5 \%$ lalu ditambahkan air, sehingga terjadi dua lapisan, lapisan atas (A-2) dan lapisan bawah (B-2). Lapisan bawah diambil dan dikeringkan dengan kalsium klorida anhidrat berlebih, lalu disaring. Filtrat dievaporasi, sedangkan residu ditempatkan dalam wadah yang berisi es. Residu kemudian ditimbang, diuji indeks bias dan bobot jenisnya serta dianalisis dengan spektrometer ${ }^{1} \mathrm{H}$ NMR.

\subsection{Sintesis Senyawa Alil Isoeugenol Eter dengan Metode Pemanasan}

Sebanyak 131,2 g (0,8 mol) isoeugenol; $96,8 \mathrm{~g}$ $(0,8 \mathrm{~mol})$ alil bromida; $110 \mathrm{~g}(0,8 \mathrm{~mol})$ kalium karbonat anhidrat dan $100 \mathrm{~mL}$ aseton dimasukkan ke dalam labu leher tiga berkapasitas $250 \mathrm{~mL}$ yang dilengkapi dengan seperangkat alat pendingin bola dan pengaduk magnetik. Sambil diaduk campuran dipanaskan dengan menggunakan pemanas water bath selama 8 jam. Setelah dingin, campuran dipindahkan ke dalam corong pisah dan ditambahkan air sebanyak $200 \mathrm{~mL}$, sehingga terbentuk dua lapisan, lapisan atas (A-1) dan lapisan bawah (B-1). Lapisan B-1 diekstrak dengan $2 \times 50 \mathrm{~mL}$ eter, terbentuk dua lapisan, yaitu lapisan atas (A-2) dan lapisan bawah (B2). Selanjutnya lapisan A-1 dan A-2 dicampur dan diekstrak dengan 2 × $50 \mathrm{~mL} \mathrm{NaOH} 2 \mathrm{M}$ sehingga terbentuk dua lapisan, lapisan atas (A-3) dan lapisan bawah (B-3). Lapisan A-3 dikeringkan dengan kalium karbonat anhidrat dan disaring. Lalu pelarut dalam filtrat dievaporasi. Residunya didistilasi fraksinasi pengurangan tekanan dengan kolom vigreoux pendek. Fraksinya dianalisis dengan GC dan spektrofotometer IR.

\subsection{Reaksi Penataan Ulang Claisen Senyawa Alil Isoeugenol Eter}

Sebanyak 8,16 g $(0,04 \mathrm{~mol})$ alil isoeugenol dimasukkan ke dalam labu leher tiga berkapasitas $250 \mathrm{~mL}$ yang telah dilengkapi termometer dan seperangkat alat pendingin bola. Lalu labu dilakukan pemanasan pada suhu $200{ }^{\circ} \mathrm{C}$ selama 30 menit. Selanjutnya tiap interval waktu tersebut, sampel diambil dengan menggunakan pipet ukur, setelah dingin ditambahkan $5 \mathrm{~mL} \mathrm{NaOH}$, selanjutnya diekstrak dengan 2 x $5 \mathrm{~mL}$ petroleum eter, sehingga terbentuk dua lapisan yaitu lapisan atas (A-1) dan lapisan bawah (B-1). Kemudian lapisan $\mathrm{B}-1$ diasamkan dengan $\mathrm{HCl} 5 \mathrm{M}$ hingga mencapai $\mathrm{pH}$ 2-3, lapisan atas (A-2) diambil dan lapisan bawah (B-2) diekstrak dengan 2 x 5 $\mathrm{mL}$ eter, terjadi lapisan atas (A-3) dan lapisan bawah (B-3). Lapisan A-2 dan A-3 digabung dan dicuci dengan air sampai netral, kemudian dikeringkan dengan natrium sulfat anhidrat dan disaring. Pelarut dalam fasa cair dievaporasi lalu residu dianalisis dengan GC, GC-MS dan spektrofotometer IR.

\section{HASIL DAN PEMBAHASAN}

\subsection{Sintesis Alil Bromida}

Sintesis senyawa alil bromida berlangsung secara eksotermis yang dilakukan dengan mereaksikan alil alkohol dan hidrogen bromida $47 \%$ (b/v) serta asam sulfat $97 \%$ (b/v) sebagai katalisnya.

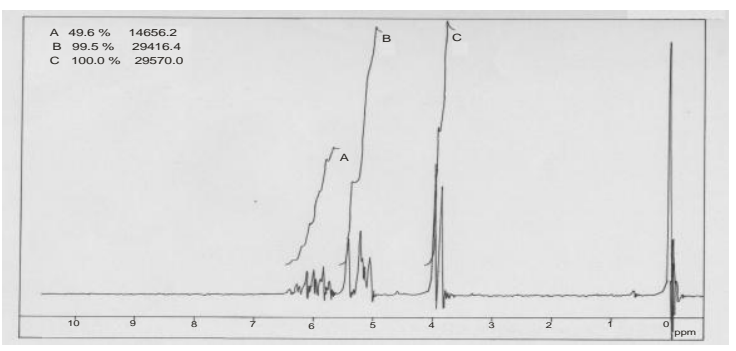

Gambar 2. Spektra ${ }^{1} \mathrm{H}$ NMR hasil sintesis alil bromida

Pergeseran kimia pada daerah 6 ppm mempunyai kenampakan multiplet dan hasil integrasinya setara dengan satu hidrogen, muncul akibat serapan gugus $=\mathrm{CH}-$, sedangkan puncak dengan kenampakan doublet pada daerah 5,5 ppm dan hasil integrasinya setara dengan dua atom hidrogen merupakan bukti adanya serapan gugus $\mathrm{H}_{2} \mathrm{C}=$ pada alil bromida. Puncak doublet dengan pergeseran kimia pada daerah 4 ppm dan hasil integrasi yang setara 
dengan dua atom hidrogen, muncul akibat serapan gugus metilen $\left(-\mathrm{CH}_{2}-\right)$.

\subsection{Reaksi alilasi isoeugenol dan Penataan Ulang Claisen}

Hasil spektra IR dan kromatogram GC-

MS produk reaksi alilasi isoeugenol menunjukkan bahwa telah terbentuk produk campuran antara alil isoeugenol eter dan produk reaksi penataan ulang Claisennya yaitu 6-alil isoeugenol.

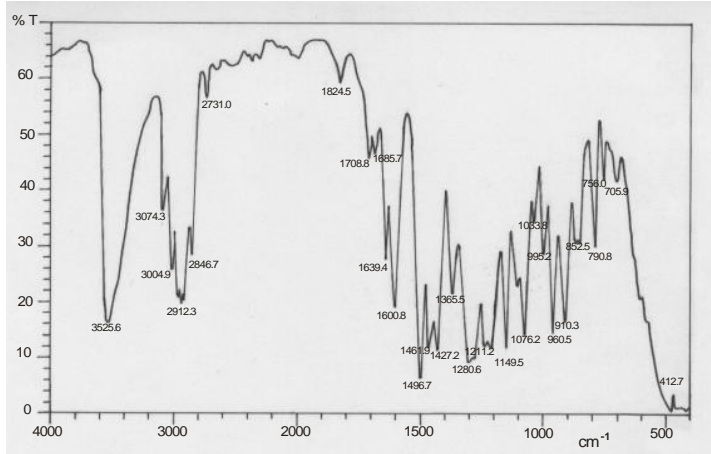

(a)

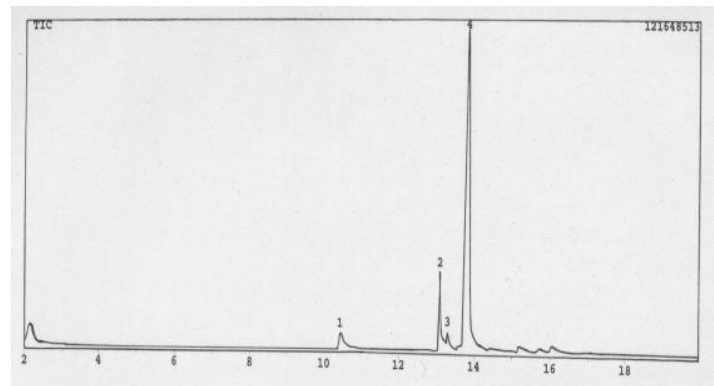

(b)

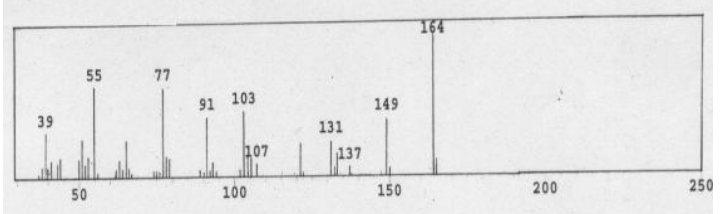

(c)

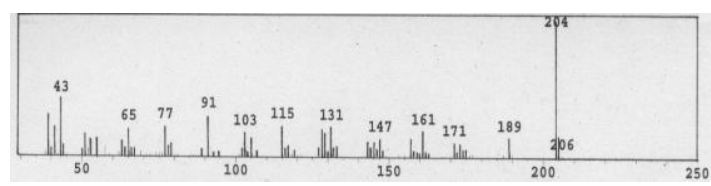

(d)

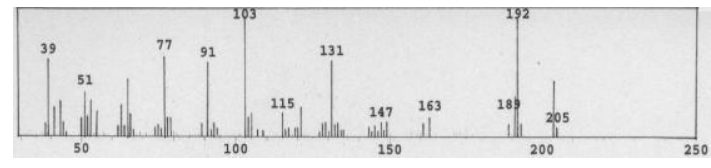

(e)

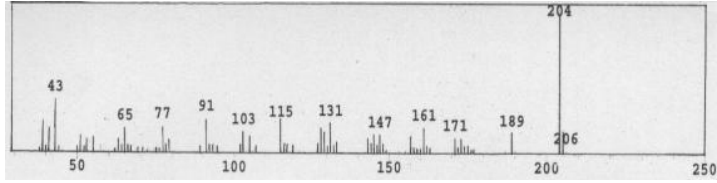

(f)

Gambar 3. (a) Spektra IR hasil reaksi alilasi isoeugenol, (b) Kromatogram GCMS hasil reaksi alilasi isoeugenol, (c) Spektra massa puncak 1 (d) Spektra massa puncak 2 (e) Spektra massa puncak 3 (f) Spektra massa puncak 4

Pada gabungan kromatogram hasil sintesis alil isoeugenol eter terlihat bahwa senyawa 6-alil isoeugenol sudah terbentuk selama proses pemanasan pada suhu $55{ }^{\circ} \mathrm{C}$ selama 8 jam (kromatogram VI) dengan rasio kemurnian alil isoeugenol eter dan 6-alil isoeugenol yaitu 1:5. Setelah evaporasi pelarut kemurnian puncak senyawa yang diduga alil isoeugenol eter menurun sebesar 3,65\% (kromatogram VII). Tahapan distilasi fraksinasi vakum dengan kolom vigreoux meningkatkan kemurnian senyawa yang diduga 6-alil isoeugenol sebesar 7,22\% (kromatogram VIII). Pemanasan pada suhu $200^{\circ} \mathrm{C}$ mengakibatkan sebagian besar senyawa alil isoeugenol eter terkonversi menjadi 6-alil isoeugenol (kromatogram IX).

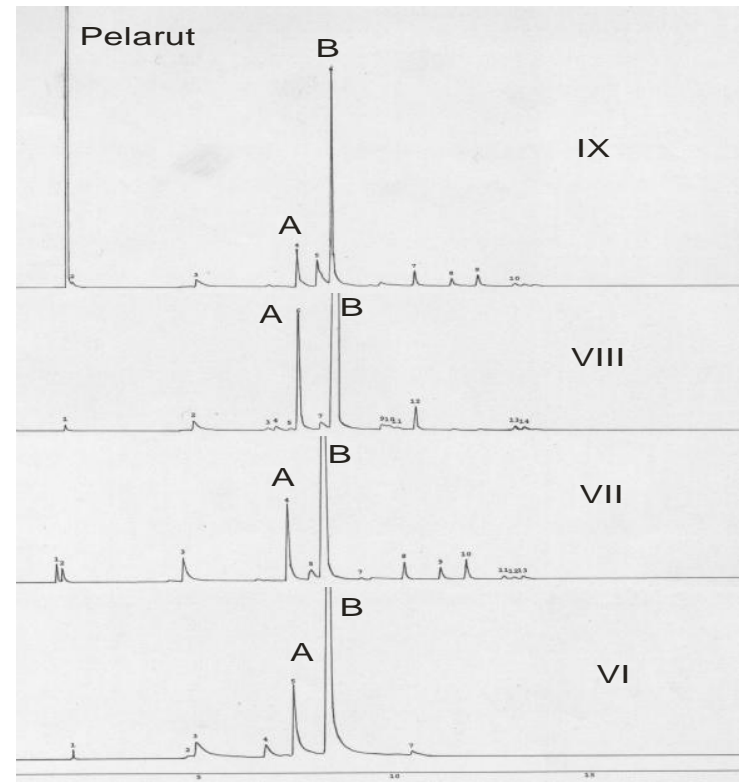

Gambar 4. Gabungan kromatogram GC produk reaksi 
Keterangan :

$\mathrm{A}=$ Alil isoeugenol eter

$\mathrm{B}=$ 6-alil-isoeugenol

$\mathrm{VI}=$ Kromatogram produk setelah pemanasan pada suhu $55^{\circ} \mathrm{C}$ selama 8 jam

VII = Kromatogram setelah evaporasi pelarut

VIII = Kromatogram destilat hasil destilasi fraksinasi

IX = Kromatogram produk pemanasan pada suhu $200^{\circ} \mathrm{C}$ selama 30 menit

Berdasarkan kromatogram-

kromatogram di atas terlihat bahwa konversi senyawa alil isoeugenol eter menjadi 6-alil isoeugenol sangat rentan terhadap panas, sehingga proses reaksi alilasi isoeugenol yang melibatkan panas menyebabkan terbentuknya produk campuran. Produk campuran yang diperoleh diduga juga berasal dari hasil reaksi kompetitif antara struktur-struktur resonansi isoeugenol dengan zat pengalilasi. Sifat kebasaan isoeugenol lebih besar daripada eugenol, hal ini menyebabkan isoeugenol merupakan nukleofil yang lebih kuat dibandingkan eugenol. Kemampuan stabilitas resonansi karbokation alil yang dapat terstabilkan oleh penyebaran muatan positif pada ikatan mengakibatkan kation alil sangat reaktif terhadap nukleofil.

$$
\stackrel{+}{\mathrm{C}} \mathrm{H}_{2}-\mathrm{CH}=\mathrm{CH}_{2} \longleftrightarrow \mathrm{CH}_{2}=\mathrm{CH}-\stackrel{+}{\mathrm{C}} \mathrm{H}_{2}
$$

Struktur resonansi isoeugenol dapat dituliskan sebagai berikut :

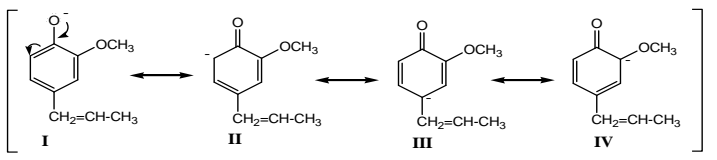

Gambar 5. Resonansi isoeugenol

Berdasarkan kestabilannya, diduga dalam reaksi alilasi isoeugenol terjadi kompetisi antara struktur resonansi isoeugenol I dan II untuk bereaksi dengan kation alil, sehingga dihasilkan produk campuran berupa senyawa eter dan senyawa fenol.
Pemanasan pada suhu $200{ }^{\circ} \mathrm{C}$ selama 30 menit menghasilkan kemurnian senyawa fenol sebesar $60,33 \%$. Terjadi penurunan kemurnian senyawa yang diduga 6-alil isoeugenol sekitar $11,25 \%$ sampai $18,47 \%$ apabila dibandingkan dengan kemurnian senyawa tersebut pada tahap-tahap proses alilasi sebelumnya. Suryanto (1996) telah melakukan reaksi penataan ulang Claisen senyawa alil eugenol eter dengan pemanasan pada suhu $200{ }^{\circ} \mathrm{C}$ selama 30 menit. Senyawa alil eugenol eter disintesis dengan metode pemanasan. Pada produk reaksi penataan ulang Claisen dihasilkan senyawa 4,6dialil-2-metoksifenol dengan kemurnian $95,17 \%$.

Berdasarkan fenomena-fenomena di atas dapat disimpulkan bahwa senyawa alil isoeugenol eter memerlukan panas yang lebih rendah daripada senyawa alil eugenol eter untuk mengalami penataan ulang Claisen. Pada kondisi reaksi penataan ulang Claisen yang sama, kemurnian produk penataan ulang Claisen senyawa alil isoeugenol eter lebih rendah bila dibandingkan dengan senyawa alil eugenol eter.

\section{KESIMPULAN}

Berdasarkan hasil penelitian dapat disimpulkan bahwa:

a. Pembuatan alil isoeugenol eter dengan metode pemanasan menyebabkan alil isoeugenol eter terkonversi menjadi produk penataan ulang Claisennya yaitu 6-alil isoeugenol.

b. Pemanasan alil isoeugenol eter pada suhu 200 oC selama 30 menit menyebabkan konversi senyawa eter menjadi senyawa fenol dengan kemurnian $60,33 \%$. 


\section{DAFTAR PUSTAKA}

Arsen'ev, V.G., Arsen'eva, M.Y., Shopin, D.V., and Olekhnovich, L.P., 2003, Synthesis and Electrophilic Substitution of Dipyrrolo-(1,2-b:3,4-d) Pyridazines, Chemistry of Heterocyclic Compounds Journal, Vol. 39, No.5

Crivello, J.V., Kong, S. and Harvilchuck, L., 1999, Synthesis of alkyl and aryl 1propenyl ether monomers : A New Approach, Journal of Macromolecular Science, Vol. 36, p. 1123-1140

Fleming, I., 1989, Frontier Orbital and Organic Chemical Reaction, John Wiley and Sons, New York

Sethi dan Rao, S., 1963, Synthesis of 4alilkatekol and Mechanism of Claisen Rearrangement in Cathecols, Ind. J. Chem., Vol 2, 435

Suryanto, E., 1996, Sintesis 4,6-dialil-2metoksifenol Melalui Penataan Ulang Claisen, Tesis, Universitas Gadjah Mada, Yogyakarta

Tamami, B. and Ghasemi, S., 2008, Nucleophilic Substitution Reaction Using Polyacrylamide-Based Phase Transfer Catalyst in Organic and Aqueous Media, Journal of The Iranian Chemical Society, Vol. 5, pp. S26-S32

Wei Tsai, T., Chi Wang, E., Rong Li, S., Hua Chen, Y., Li Lin, Y., Feng Wang, Y. and Shiang Huang, K., 2004, A New Synthesis of Benzofurans from Phenols Via Claisen Rearrangement and RingClosing Metathesis, J. Chin. Chem. Soc., 51, 1307-0318 